\title{
Expressing Identity and Shaping Image: The Relationship Between Corporate Mission and Corporate Sponsorship
}

\author{
Stephanie Cunningham \\ University of Queensland \\ T. Bettina Cornwell \\ University of Michigan \\ Leonard V. Coote \\ University of Queensland
}

\begin{abstract}
Despite the popularity of sponsorship-linked marketing programs, we know little about how firms form sponsorship policies. This article describes a corporate identitysponsorship policy link and offers empirical support for it via a mixed method research design. Content analysis of 146 Fortune 500 companies' online sponsorship policies and mission statements is followed by cluster, factor and multinomial regression techniques. Results show that corporate identity, as reflected in mission statements, matters to sponsorship policy. Specifically, companies emphasizing financial success in their mission statements prefer to sponsor individual athletes, education, the environment and health-related activities. Alternatively, companies stressing the importance of employees demonstrate a propensity to sponsor team sports, entertainment, religious, community, charity and business related activities. Reasons for these strategic differences are discussed.
\end{abstract}

The role of sponsorship within marketing strategies is expanding rapidly. In fact, International Events Group Network (IEG Inc., 2005) has asserted that corporate sponsorship is the world's fastest growing marketing tool. Identifying any large scale or public event sans sponsorship is virtually impossible (Kover, 2001). Thus, worldwide sponsorship spending at $\$ 38$ billion in 2007 is unsurprising. Despite rapid expansion in practice, sponsorship research is a relatively new pursuit within the academic ambit (Dolphin, 2003). Previous research within the field focuses primarily on sponsorship and its related outcomes such as brand awareness (e.g., McDonald, 1991) and brand equity (e.g., Cornwell, Roy, \& Steinard, 2001). Meanwhile, very little research in extant literature focuses on the managerial and strategic role of sponsorship (Gwinner \& Eaton, 1999). Managerial

Cunningham and Coote are with the University of Queensland Business School, University of Queensland, Australia. Cornwell is with the Sport Management Program, University of Michigan, Ann Arbor, MI 48109. 
research to date focuses primarily on sponsorship objectives, audience, organizational structure, personnel requirements, and budgeting (Cornwell \& Maignan, 1998) in opposition to the processes and corporate instruments practitioners can use to effectively manage their sponsorship programs.

A starting point for understanding the role corporate sponsorship might play in shaping the image of the firm is to understand the ways in which organizational identity and image relate. Hatch and Schultz (2002) have argued that organizational identities are required to cope with increasing amounts of exposure to the media and escalating levels of access by stakeholders. A firm's engagement with a major sponsorship of sport, art or cause, interestingly, heightens both exposure and access. Most major sponsorships in any category are accompanied by media coverage, in fact, media coverage is aggressively sought in most sponsorship relationships; and the sponsorship contract brings previously distant stakeholders into close proximity.

Given increased exposure and access as a backdrop, the organization according to Hatch and Schultz must construct identity via negotiation between organizational culture and organizational images. This is accomplished through: (1) mirroring (the process by which identity is mirrored in the images of others); (2) reflecting (the process by which identity is embedded in cultural understanding); (3) expressing (the process by which culture makes itself known though identity claims); and, (4) impressing (the process by which expressions of identity leave impressions on others; Hatch \& Schultz, 2002). If we accept organizational image as the set of views on the organization held by those who act as the organization's external stakeholders (Hatch \& Schultz, 2002), then clearly sponsorship may play a role in shaping image. As an example, the image of Ferrari can be attributed in part to that organization's long-term association with sponsorship of Formula 1 racing (Amis, 2003).

Moreover, it could be argued that sponsorships can play a somewhat unique role in mirroring, reflecting, expressing and impressing. As Cheney and Christensen (2004) have explained, marketing and advertising are communicating both externally and internally, "hoping to influence both consumers and stakeholders and to confirm the sending organization's own merits or good intentions. This way, market-related communication seeks to link internal and external audiences around the same concern, identity" (emphasis added, p. 529). That is to say, sponsorships allow organizations to communicate reflexively, with themselves, when addressing external stakeholders and thus to build and confirm organizational identity. In summarizing the dynamics of organizational identity, Hatch and Schultz (2002) have stated that "organizational identity is not an aggregation of perceptions of an organization resting in people's heads, it is a dynamic set of processes by which an organization's self is continuously socially constructed from the interchange between internal and external definitions of the organization offered by all organizational stakeholders who join in the dance" (p. 1004). Clearly, major sport teams, individual athletes, charity and arts organizations being sponsored by a firm are part of this dance.

Building brand image and awareness are the most prevalent sponsorship objectives (Cornwell \& Maignan, 1998; Walliser, 2003) and are perhaps the most frequently researched perspectives. Of the many brand level papers, two have sought to explore the potential of sponsorship to build brand identity; one with a focus on the potential of cobranding between brand and event to build brand iden- 
tity (Motion, Leitch, \& Brodie, 2003) and the other with a focus on the role of fit in building brand identity (Becker-Olsen \& Hill, 2006). Less is said and less empirical investigation has been devoted to understanding the role sponsorship plays in corporate image and the link between identity and image has been left unexplored. The few voices on corporate image such as McDonald (1991), have suggested that sponsorship has significant power in altering or boosting corporate image. Javalgi, Traylor, Gross, and Lampman (1994) have suggested sponsorships can enhance corporate identity. The rationale behind such enhancement is that each sponsorship activity has identifiable image values that transfer onto the sponsoring firm. Image perceptions increase when sponsor and sponsee share characteristics (Javalgi et al., 1994) and have favorable images and high visibility (Stipp \& Schiavone, 1996). Similarly, Grimes and Meenaghan (1998) have purported that a well chosen sponsorship has significant power in projecting desired values of a firm and thereby creates a distinct and favorable brand image among a firm's publics. The remaining work in the area is made up of case studies such as the one by Lachowetz, Clark, Irwin, and Cornwell (2002) that considers corporate image impressions derived from sponsorship of a combined golf-charity event and work by Rajaretnam (1994) that advocates for one company the blending of sponsorship and advertising to achieve the best image results.

\section{Conceptual Framework}

If organizations acknowledge the potential value of sponsorships in contributing to corporate image, how then do they select events or activities to sponsor that align with their core values and philosophies? Conversely, how do they avoid sponsoring on the grounds of an image conflict? One solution is through the use of a sponsorship policy that explicates what a company will sponsor, as well as what it will not sponsor, which audiences should be targeted, the quantity of sponsorships that should be undertaken over a given period, and the level of sponsorship devoted to each event (Cornwell, Weeks, \& Roy, 2005). At present, the literature overlooks the role of sponsorship policies.

In developing image, how does a firm combine sponsorships like sport and arts or entertainment and charity to form a consistent picture? A communication policy should support and project a firm's mission, philosophy, and goals (Gilsdorf, 1987). Furthermore, corporate identity engenders corporate image, as corporate image is formed by consumers perceiving and interpreting the corporate identity (Alessandri, 2001). Given that policy is founded on corporate values, firm sponsorship policy and consequent practice should directly project the firm's corporate identity into the marketplace. Therefore, this research investigates the role of policy in strategic sponsorship and corporate image management.

Returning to the dynamics of organizational identity (Hatch \& Schultz, 2002), we can see a role for sponsorship in each process previously described. In sponsorship, an organization becomes connected to a property through a contract. Just as Dutton and Dukerich (1991) found in their study of the Port Authority of New York, when the homeless issue was mirrored by stakeholders as the Port's issue, this reflection had to be addressed. So too do the issues of, for example, a sponsored sport team reflect on a sponsoring organization. Even the behavior of fans of teams is reflected to the sponsors. Sponsorship can also provide a context where 
an organization's identity can be reinforced by allowing individuals to reflect on their organization (Berger, Cunningham, \& Drumwright, 2006). For example, when a firm sponsors a cause like Habitat for Humanity, the employee participation in building a home for those in need embeds identity in the organization's culture. Sponsorship can perhaps more readily be seen in the roles of expressing organizational culture and impressing on others' corporate identity claims. For example, the decision to sponsor opera is very different than the decision to sponsor community recycling. An organization can use sponsorship as a symbolic expression of organizational identity, one that makes the firm distinctive. In addition to advertising, public relations, social responsibility, and seemingly less powerful elements such as logo (Henderson \& Cote, 1998) and corporate font type (Henderson, Giese, \& Cote, 2004), sponsorship can project images to others and arguably does so in an emotionally powerful way. Therefore, the question underpinning this research is: How does corporate identity translate into sponsorship policy which in turn helps to build a corporate image within the marketplace?

To answer this question we focus primarily on sponsorship selection and thus on the dynamic of expressing identity through the types or categories of sponsorship selected from the vast field of options available to the organization. On the one hand, corporate identity has long been held to be that which is central, distinctive, and enduring in a firm (Albert \& Whetten, 1985). On the other hand, we have accepted that corporate identity is a dynamic interplay between internal and external stakeholders. Corporate identity continually molds corporate image as it conveys the qualities of a firm that an audience perceives and interprets as image. Gray and Balmer (1998) have suggested that it is interaction and experience with a corporate identity that produces an image within the minds of the public. Therefore, corporate identity claims should be expressed in the sponsorship decision making of the firm and identity claims should predict sponsorship choice.

A mission statement is one type of summary projection of corporate identity (Alessandri, 2001). A mission statement is thought to be necessary in helping a company form its identity and is purported to be the starting point for consultants specializing in corporate identity programs (Leuthesser \& Kohli, 1997). Mission statements have been the focus of empirical studies of identity because they are thought to represent "prototypical examples of organizational identity claims" (Ran \& Duimering, 2007, p. 163). This being the case, it must also be noted that mission statements have been criticized as an indication of true organizational identity because they tend to reflect the "official" or managerial view of the organization (Meyer \& Rowan, 1977) or at least a view of the organization that is constructed in response to institutional pressures (Peyrefitte \& David, 2006).

It may, however, be that the time of mission statements housing large discrepancies between what organizational members hold as meaningful and what managers and other officials project as meaningful has passed. Hatch and Schultz (2002) point out that one implication of increasing access to organizations is that organizational culture is now more open for scrutiny. We argue that these same pressures push organizations to make policies, such as sponsorship policies, and documents such as mission statements decidedly public. That these policies and documents are available on the Internet is evidence that they are projections intended for any and all stakeholders, as well as business analysts and the media. Although this is a larger point to be taken up in future research, we argue that 
increased access and exposure to critical views should force greater alignment between what managers say in mission statements and what organizational members at every level see as the mission of the organization.

In the current study, a firm's mission statement is used as a proxy of corporate identity since it is relatively available (Ran \& Duimering, 2007). In addition, since a typical mission statement is generally quite succinct, those concepts explicitly mentioned in the mission statement are being put forward as the firm's most defining, idiosyncratic and important values and are thus appropriate for the content analysis approach employed here. We acknowledge that mission statements are, at best, only a partial representation of expressed identity. If they are, however, shown to be related to sponsorship policy, we have the opening of a new line of inquiry in sponsorship research. Thus, two exploratory but measurable hypotheses are offered.

$\mathrm{H}_{1}$ : Corporate identity, as expressed in mission statement values, predicts what a firm will sponsor.

$\mathrm{H}_{2}$ : Corporate identity, as expressed in mission statement values, predicts what a firm will not sponsor.

The next section describes a test of these hypotheses.

\section{Method}

Since a number of data collection, data reduction and analyses are undertaken in the following sections an overview is provided in Figure 1.

\section{Sampling}

The sample frame for this research comprises the sponsorship policies and mission statements retrieved from Fortune 500 company Web sites. Fortune magazine ranks the largest companies in the United States each year by revenue. The rationale for selecting these firms hinges on availability and representativeness. Because Fortune 500 companies are some of the most financially successful entities in the world, they likely have an easily accessible Web site (including information on policies and missions) and have large enough marketing budgets to include marketing strategies such as sponsorship. In terms of representation issues, Fortune 500 companies vary by size, industry and geographical location and provide a varied and representative sample frame.

In the second half of 2005, all $500 \mathrm{Web}$ sites were visited and searched for sponsorship policies and mission statements. Several steps ensured uniformity in the retrieval process. When seeking sponsorship policies, if they could not be readily found, a search was conducted within the confines of the Web site for terms such as sponsorship policy and sponsorship guidelines. If the policy existed as a standalone document, the search often provided a direct link to it. If it was embedded within another document (e.g., charitable contributions, corporate giving, community funding) the search results provided a link to the appropriate document. A similar process yielded mission statements. If a mission statement was not readily located, a search within the Web site for mission statement or corporate values was undertaken. If the policy, mission statement, or both were inaccessible, the website search was abandoned. 


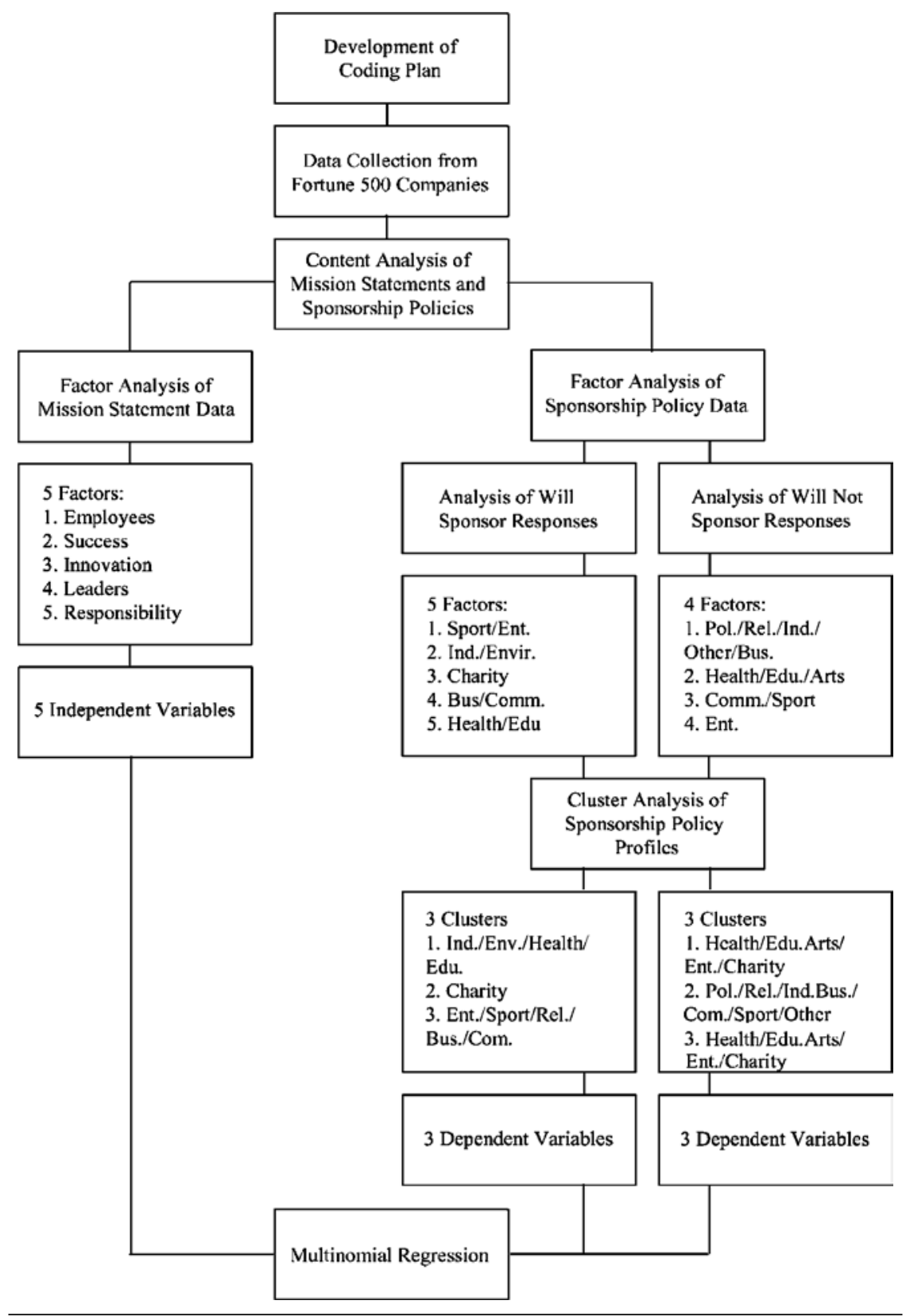

Figure 1 - Data collection, reduction and flow of analysis. 
From $500 \mathrm{Web}$ sites considered, $166 \mathrm{Web}$ sites contained both policies and mission statements. Of these, 20 policies were discarded: 12 for content related issues (e.g., it was a list of their current sponsorships as opposed to guidelines or a policy) and eight of these for mission statements issues (e.g., it was a summary of their corporate operations as opposed to their mission or values). The final sample consisted of 146 cases, representing an inclusion rate of $29.2 \%$. It is not concluded that the residual firms do not have sponsorship policies. It is possible that they have chosen to not make their policies available online.

\section{Content Analysis}

The first phase of the study is a content analysis of the sponsorship policies and mission statements. The content analysis follows steps proposed by Insch, Moore, and Murphy (1997). The steps taken were (1) identify the questions and the constructs involved, (2) identify the texts to be examined, (3) specify the unit of analysis, (4) specify the categories, (5) generate the sampling coding scheme, (6) pretest the coding scheme, (7) purify the coding scheme, (8) collect data, (9) assess reliability, (10) assess construct validity, and (11) analyze data. Given the potential subjectiveness of content analyses, this set of specific criteria guided the coding process to maximize reliability of the results. Briefly, in specification of the categories, an iterative process reached agreement on content categories between two researchers. A random sample (20\%) of coded policies/missions was subsequently recoded by a third additional coder unfamiliar with the research hypotheses to assess reliability. All of these policies were coded identically the second time (100\% interjudge reliability). The reliability measures of this content analysis yielded such successful results largely due to the refinement and modification of the coding scheme to produce clear and consistent coding procedures. Construct validity or confidence that the classification scheme measures what it is intended to measure was assess by the reduction of disagreements between coders. Importantly, categories not successful in discriminating between constructs were collapsed.

Before final coding the sponsorship policies, 13 Will Sponsor and 13 Will Not Sponsor categories were derived from popular press accounts of sponsoring using the content analysis process outlined. The source for news accounts of sponsorship categories was the database Factiva. This electronic resource, offered by the Dow Jones company, includes newswires, major news and business publications as well as industry reports. Searches on terms such as "corporate sponsorship" and "deal" or "contract" yielded thousands of accounts of sponsorship. These were reviewed for this and another project until conceptual saturation was reached. That is to say, reviewing continued until more accounts of sponsorship contracts yielded no new categories.

For subsequent statistical analyses, having numerous categories allows combinations to naturally emerge from the data (Insch et al., 1997). The categories are Sports (primarily team sports), Arts, Entertainment, Charity, Community, Business ("for profit" organizations), Politics, Religion, Education, Health, Environment, Individuals (primarily individual athletes and sports personalities), and Other. This last miscellaneous category, on review, essentially referred to sponsorships involving alcohol, tobacco and other controversial areas. Importantly, while 
sponsorship policies have not received a great deal of researcher attention to date, policy issues related to sponsorship by firms selling tobacco have (Cornwell, 1997; Dewhirst \& Hunter, 2002). Thus, cosponsorship of an event with a tobacco, alcohol or gambling sponsor is viewed negatively by some firms and prohibited by their sponsorship policy because the stigmatized image of a controversial sponsorship rubs off on other sponsors (Ruth \& Simonin, 2003). Because the Other category became meaningful in capturing policies regarding controversial sponsorships, it was retained in the subsequent analysis.

Similarly, 13 mission statement themes emerged from the Factiva database and from review of corporate attributes espoused in mission statements and visions. At this point a brief digression to consider the relationship of identity theory to the cross-sectional nature of the data seems needed. The vast majority of work on organizational identification theory deals with an organization located within a competitive context. For example, Albert and Whetten (1985) in discussing the criterion of claimed distinctiveness have explained that it is the "features that distinguish the organization from others with which it may be compared" (emphasis added, p. 90). Other researchers have emphasized optimal distinctiveness from competitors (Brewer, 2003) and distinctiveness as competitive advantage (Barney \& Stewart, 2000). Because our data are across various industries it is possible to pick up identity concepts that are distinctive within an industry segment but repeated across various industries. Thus, as Albert and Whetten (1985) defined, identity is central, enduring, and distinctive, but distinctiveness is cast against direct competitors.

Mission statement categories established in this content analysis included: Company Success, Product Superiority, Focus on Competitors, Innovation, Being the Best, A Focus on Customers, Diversity, Value, Ethics, An Employee Focus, Being Helpful, Responsibility, and Improving Quality of Life. This listing, although more specific so to capture expressed identity claims, does nicely reflect the mission statement categories found by Hackley (1998). In UK mission statements, Hackley found nine types of statements expressing: purpose, behaviors, strategy, values, concern for customers, philosophy, self-concept, concern for public image, and concern for employees. Given that Hackley argued that US mission statements were more comprehensive than UK mission statements, one would only expect more categories in this U.S. sample. Use of 13 categories in both sponsorship and mission statements is coincidental.

Coding of all 146 sponsorship policies and mission statements closed the first phase of the study. Although it was a qualitative procedure, several steps (i.e., specific categories, single classification) ensured quantitative analysis could be performed on the results.

\section{Sample Characteristics}

The content analysis recorded characteristics of each firm: size as measured by number of employees, rank in the Fortune 500, industry, geographic focus, and customer focus (Business to Business (B2B), Business to Consumer (B2C), or both). Information from Hoovers Industry Analysis helped to classify the firms according to size, industry, geographic and customer focus. Refer to Table 1 for 
Table 1 Industry Breakdown of Fortune 500 Firms: Population and Sample Statistics

\begin{tabular}{|c|c|c|c|}
\hline Industry & $\begin{array}{l}\text { Number } \\
\text { of Firms }\end{array}$ & $\begin{array}{l}\text { Population } \\
\text { Percentage }\end{array}$ & $\begin{array}{c}\text { Sample } \\
\text { Percentage }\end{array}$ \\
\hline Energy and utilities & 61 & 12.2 & 18 \\
\hline Retail & 57 & 11.4 & 0 \\
\hline Insurance & 40 & 8.0 & 9 \\
\hline Health care & 28 & 5.6 & 5 \\
\hline Industrial manufacturing & 28 & 5.6 & 4 \\
\hline Consumer manufacturing & 24 & 4.8 & 7 \\
\hline $\begin{array}{l}\text { Computer hardware and } \\
\text { software }\end{array}$ & 21 & 4.2 & 7 \\
\hline Construction & 21 & 4.2 & 1 \\
\hline Financial services & 20 & 4 & 13 \\
\hline Auto transport & 19 & 3.8 & 2 \\
\hline Telecommunications & 18 & 3.6 & 0 \\
\hline Transport & 18 & 3.6 & 0 \\
\hline Banking & 17 & 3.4 & 6 \\
\hline Food & 17 & 3.4 & 5 \\
\hline Electronics & 16 & 3.2 & 4 \\
\hline Chemistry & 15 & 3 & 5 \\
\hline Pharmaceuticals & 12 & 2.4 & 2 \\
\hline Leisure & 11 & 2.2 & 3 \\
\hline Aerospace and defense & 9 & 1.8 & 2 \\
\hline Media & 9 & 1.8 & 3 \\
\hline Beverages & 7 & 1.4 & 1 \\
\hline Business services & 7 & 1.4 & 1 \\
\hline Metals and mining & 6 & 1.2 & 1 \\
\hline Agriculture & 3 & .6 & 0 \\
\hline Real estate & 3 & 6 & 0 \\
\hline Environmental services & 2 & .4 & 1 \\
\hline Education & 1 & .2 & 0 \\
\hline Consumer services & 0 & 0 & 0 \\
\hline Security & 0 & 0 & 0 \\
\hline Unidentified industries & 10 & 2 & 0 \\
\hline
\end{tabular}

the breakdown of firms with regard to these characteristics. Variation across sectors suggests a relatively representative sample was obtained but with an under representation of retail firms and an over representation of financial firms. Sponsorship policy specifications, mission statement, and sample characteristics were analyzed through factoring, clustering, and regression analysis, the results of which are now presented. 


\section{Results}

Before performing the statistical analysis, the categories of the content analysis were coded as dummy variables. A total of 39 variables were submitted for analysis (13 Will sponsor categories, 13 Will Not sponsor categories, and 13 mission statement themes). The following describes how each variable was formed.

\section{The Dependent Variable: Sponsorship Type}

Two dependent variables were formed from the Will (DV1) and Will Not (DV2) sponsorship categories, please refer to Figure 1. While Will sponsor categories can be expected to reflect corporate values, to be thorough, Will Not sponsorship categories are included to capture any anti values. It should be noted that these are the types of sponsorships the firm is willing or unwilling to undertake and may not reflect the actual sponsorships held in the firm's portfolio at the time of the study.

DV1: Will Sponsorship Category. A principal component factor analysis was performed on 12 of the initial 13 Will sponsorship categories. Before conducting the analysis, the political category of sponsorships was removed; although identified in the review of literature, no firm sponsored political events or candidate's organizations. The correlation matrix revealed that the input variables were sufficiently correlated and Bartlett's Test of Sphericity was 165.04, significant at the .001 level. The communalities were all high (maximum $=.79$ ), indicating that the estimated model explained a substantive amount of variance in the observed variables. The number of factors extracted, as descriptors of variance within the data, was based on selecting factors with Eigenvalues exceeding one as well as the total amount of variance explained by these factors. Five factors had Eigenvalues over one: factors one (2.06), two (1.66), three (1.23), four (1.13) and five (1.03), together explaining $59.16 \%$ of variance within the data, refer to Table 2 for a full summary of factor loadings, Eigenvalues and other variance measures.

To make sense of these factors, the pattern matrix was interpreted. A cutoff point for loadings of .45 was applied to all factor analyses (Hair, Anderson, Tatham, \& Black, 1998). Entertainment (.69), sport (.72), and religion (.51) sponsorships load highly on factor one. Individuals (.75) and environment (.62) sponsorships load highly on factor two. Factor three is characterized by a strong focus on charity (.87) and away fromarts (-.57). Business (.75) and community (.63) are integral to factor four while health (.75) and education (.65) load highly on the fifth factor.

Factors were then labeled according to their characteristics: factor one as Sport/Entertainment, factor two as Individuals/Environment, factor three as Charity, factor four as Business/Community, and factor five as Health/Education. Arts does not load significantly on any factor; except for factor three, but its negative sign suggests an anti arts specification, as with the category of Other. It is not surprising that Other does not load significantly on any factor as it includes controversial sponsorships (e.g., cosponsorship with tobacco and alcohol) that would be likely to align sponsors with undesired values and thus negatively impact their corporate image. Therefore, Arts and Other are omitted from the labeled categories. From here, factor scores, a standardized composite measure produced for 
Table 2 Pattern Matrix, Eigenvalues, Percent Variance Explained: Will Sponsor (DV1)

\begin{tabular}{|c|c|c|c|c|c|}
\hline & Factor One & $\begin{array}{c}\text { Factor } \\
\text { Two }\end{array}$ & Factor Three & Factor Four & Factor Five \\
\hline Sport & .72 & -.08 & -.18 & .05 & -.39 \\
\hline Arts & -.06 & .17 & -.57 & .01 & .25 \\
\hline Entertainment & .69 & -.10 & -.03 & -.21 & -.10 \\
\hline Business & .29 & -.31 & .07 & -.75 & -.15 \\
\hline Charity & -.04 & .22 & .87 & .03 & .10 \\
\hline Religion & .51 & .03 & .16 & .09 & .19 \\
\hline Individual & -.11 & .75 & .06 & .05 & -.27 \\
\hline Community & -.22 & .26 & -.03 & -.63 & .29 \\
\hline Health & -.46 & -.23 & .06 & -.08 & .75 \\
\hline Education & -.44 & .13 & -.18 & .14 & .65 \\
\hline Environment & -.44 & .62 & .03 & -.09 & .24 \\
\hline Other & .01 & -.28 & .12 & .39 & .052 \\
\hline Eigenvalue & 2.06 & 1.66 & 1.23 & 1.13 & 1.03 \\
\hline $\begin{array}{l}\text { Percent of } \\
\text { variance } \\
\text { explained }\end{array}$ & 17.17 & 13.81 & 10.22 & 9.40 & 8.56 \\
\hline $\begin{array}{l}\text { Percent } \\
\text { cumulative } \\
\text { variance } \\
\text { explained }\end{array}$ & 17.17 & 30.98 & 41.20 & 50.60 & 59.16 \\
\hline
\end{tabular}

each observation for each extracted factor, were produced for inclusion in subsequent analyses (Hair et al., 1998).

Performing a cluster analysis on the five factors indicated whether they gravitated toward homogenous groups (Saunders, 1994). This allows one to see on an elementary level if certain groups of firms are more aligned with the sponsorship of certain types of events/activities. Due to the exploratory nature of this study, as well as the fact that there was no a priori conception of how many clusters should be formed, two, three, four and five cluster solutions were created. A hierarchical clustering procedure based on the agglomeration of cases was implemented. Average linkage was the measure of distance in each cluster while correlational measures were used as a measure of association among clusters. In addition, a dendrogram was produced for a visual inspection of the clustering solution.

Results showed a strong inequality among clusters in the five and four firm cluster solution, while the two and three cluster solutions were more balanced. Because three factors offer a more detailed understanding than two, only the three cluster solution was retained and used in future analysis. The next step involved profiling each of the clusters according to particular sponsorship categories (factor scores), using an ANOVA where the clusters were the dependent variable and the factor scores for sponsorship type were the independent variables. In this cluster solution, all sponsorship categories differed across the three firm clusters: Sport/ Entertainment $(F=11.68, p<.001)$, Individuals/Environment $(F=7.76, p=$ 
$.001)$, Charity $(F=79.19, p<.001)$, Business/Community $(F=9.97, p<.001)$, and Health/Education $(F=53.43, p<.001)$. Cluster one firms had a propensity to sponsor Individuals, Environment, Health, and Education, cluster two firms sponsored Charity, and cluster three firms sponsored Entertainment, Sport, Religion, Business, and Community events.

DV2: Will Not Sponsorship Categories. Analyzing the Will Not sponsorship categories followed the same process of factoring and clustering. Note that no firm refused to sponsor environmental events, and therefore, the Environment category was removed from the analysis. The correlation matrix indicated high multicollinearity thus verifying that assumptions were met and Bartletts Test of Sphericity (.74) was significant at the $p<.001$ level. Furthermore, high communalities were achieved (maximum $=.77$ ). Eigenvalues and total variance explained scores were used to extract factors. Four factors have Eigenvalues which exceeded one: factors one (3.34), two (1.53), three (1.09) and four (1.02). These four factors together explain $58.12 \%$ of total variance within the data. Refer to Table 3 for a full summary of factor loadings, Eigenvalues, and other variance measures.

The pattern matrix indicated variables loading highly on each factor. Political (.80), Religion (.79), Individual (.774), Other (.73), and Business (.69) sponsorships all loaded highly on factor one. Factor two is characterized by Health (.78), Education (.61) and Arts (.60). Community (.80) and Sport (.55) load highly on factor three, while Entertainment (.88) and Not Charity (.46) load highly on factor four, resulting in four categories of events or activities that firms will not sponsor.

Table 3 Pattern Matrix, Eigenvalues, Percent Variance Explained: Will Not Sponsor (DV2)

\begin{tabular}{lcccc}
\hline & Factor One & Factor Two & Factor Three & Factor Four \\
\hline Sport & .31 & -.03 & .55 & -.02 \\
Arts & .03 & .60 & .19 & -.03 \\
Entertainment & .00 & -.23 & .12 & .88 \\
Charity & .03 & -.32 & .10 & -.46 \\
Business & .69 & .07 & -.11 & .22 \\
Political & .80 & -.19 & .03 & -.19 \\
Religion & .79 & .15 & -.07 & -.15 \\
Individual & .77 & .01 & .10 & -.02 \\
Community & -.07 & .10 & .80 & .05 \\
Health & .09 & .78 & -.27 & -.01 \\
Education & -.01 & .61 & .37 & -.04 \\
Other & .73 & .02 & .10 & .04 \\
\hline Eigenvalue & 3.34 & 1.53 & 1.09 & 1.02 \\
Percent of variance & 27.81 & 12.73 & 9.08 & 8.50 \\
$\quad$ explained & & & & \\
Percent cumulative & 27.81 & 40.54 & 49.62 & 58.12 \\
$\quad$ variance & & & & \\
$\quad$ explained & & & & \\
\hline
\end{tabular}


The first category is labeled Political/Religious/Individuals/Other/Business, the second Health/Education/Arts, the third Community/Sport, and the fourth Entertainment. Factor scores produced for each of these factors were used in subsequent analysis

Similar to the development of the Will Sponsor variable, cluster analysis was performed on Will Not Sponsor factors to identify if any homogenous groups of firms existed in terms of what they will not sponsor. Average linkage clustering based on correlations among variables was again used as a measure of association. The dendrogram indicated a three cluster solution was appropriate. This yielded 28 cases in cluster one, 17 in cluster two and 53 in cluster three. Despite the slight inequality between the largest and smallest cluster, the three cluster solution was carried through to the next stage in the analysis.

The firm clusters were then profiled according to the Will Not sponsorship categories. An ANOVA was conducted with clusters as the dependent variable and the Will Not factor scores as the independent variables. In the three cluster solution, factor one $(F=87.03, p<.001)$, factor two $(F=47.80, p<.001)$, factor three $(F=6.61, p=.011)$ and factor four $(F=12.69, p<.001)$ all differ across clusters. Clusters one and three, similar in categories but differing in pattern, refuse to sponsor Health, Education, Arts, Entertainment, and Charity, and cluster two refuses to sponsor Political, Religious, Individuals, Business Oriented, Community, Sport and Other (e.g., tobacco, alcohol) events or activities. In summary, combined approach of factor and cluster analysis of the sponsorship categories generated the dependent variables of the study (i.e., a classification of firms according to sponsorship types). The next section details how the independent variables, the mission statement themes, were formed.

\section{The Explanatory Variables: Mission Statement Themes}

The explanatory variables were formed through an analysis of recurring themes in mission statements. Analogous to the sponsorship categories, 13 original themes were subjected to a principal component factor analysis. The correlation matrix indicated that the variables were sufficiently correlated and Bartlett's Test of Sphericity was 109.15 (significant at the .01 level), suggesting that the correlation matrix is statistically different from zero. Finally, the communalities are all high $($ maximum $=.71)$.

Similar to the process described for the dependent variable, the Eigenvalues and percent of variance explained were used to extract the appropriate number of factors. Five factors had Eigenvalues exceeding one: factors one (1.81), two (1.44), three (1.30), four (1.23), and five (1.10). These five factors explain a total variance of $52.87 \%$ (refer to Table 4 for a full summary of factor loadings, Eigenvalues and other variance measures).

To see variables loading highly on each factor, the pattern matrix was observed. Again, .45 was used as a cutoff point for high or low factor loadings. Factor one demonstrates a strong focus on employees (.73) and ethics (.66), and de-emphasis on the quality of products and services (-.54). Factor two is characterized largely by company success (.81) and value (.53). Factor three shows a strong propensity for innovation (.70) but a de-emphasis on customer needs (-.70). Factor four is driven by being the best (.70) and not with helping 
Table 4 Pattern Matrix, Eigenvalues, Percent of Variance Explained: Mission Statement Themes (IV)

\begin{tabular}{|c|c|c|c|c|c|}
\hline & Factor One & actor Two & Factor Three & Factor Four & Factor Five \\
\hline Success & .01 & .81 & -.24 & -.08 & -.11 \\
\hline Products & -.54 & -.07 & -.06 & .27 & -.21 \\
\hline Competence & .03 & -.03 & .02 & .00 & -.67 \\
\hline Innovation & .09 & -.30 & .70 & -.18 & .07 \\
\hline The best & -.07 & -.15 & .08 & .70 & -.03 \\
\hline Customer focus & -.10 & -.16 & -.70 & -.17 & .26 \\
\hline Diversity & .02 & .40 & .23 & -.51 & -.19 \\
\hline Value & -.07 & .53 & .29 & .14 & .39 \\
\hline Ethics & .66 & .11 & .03 & .14 & .25 \\
\hline Employment & .73 & -.17 & .12 & .01 & -.16 \\
\hline Help & -.11 & -.30 & -.00 & -.63 & .05 \\
\hline Responsibility & .28 & -.15 & -.16 & -.06 & .61 \\
\hline Quality & -.37 & -.04 & .32 & -.02 & .24 \\
\hline Eigenvalue & 1.81 & 1.44 & 1.29 & 1.23 & 1.10 \\
\hline $\begin{array}{l}\text { Percent of } \\
\text { Variance }\end{array}$ & 13.93 & 11.07 & 9.95 & 9.45 & 8.47 \\
\hline $\begin{array}{l}\text { Percent } \\
\text { Cumulative } \\
\text { Variance }\end{array}$ & 13.93 & 25.00 & 34.95 & 44.49 & 52.87 \\
\hline
\end{tabular}

customers/communities (-.63) or diversity (-.51). Finally, factor five demonstrates a strong focus on responsibility (.61) but no interest in competitors and their strategies (-.67).

Subsequently, factor one is labeled Employees (due to this strong focus on employees and content coded terms such as people are our greatest asset and emphasis on rewarding our workforce); factor two is titled Success (pertaining largely to financial success, profits, and return on investment); factor three is labeled as Innovation (after demonstrating propensity to innovate); factor four is titled Leadership based on the pursuit of being the best in a field; and, factor five is labeled as Responsibility based on its strong focus on social responsibility and lack of concern for other issues such as competitors. Akin to the sponsorship categories, factor scores were created for each of these five variables and used in further analysis.

\section{Regression Models}

After forming the dependent and explanatory variables, a multinomial regression analysis was performed to determine how sponsorships, Will and Will Not (DVs), are predicted by mission statement themes (IVs).

DV1: Will Sponsorship Category. The analysis involved a multinomial regression on the three cluster Will sponsor solution. This model was found to be significant 
at the .10 level with a chi square value of 18.09 . The Negelkerke $\mathrm{R}^{2}$ was 13.5 , indicating that the model explains $13.5 \%$ of variance in Will sponsor decisions. Initially this figure seems low, but when considering how many factors influence sponsorship decisions, for example: budgets, management preferences, and marketing objectives, it is actually quite a reasonable result.

The Wald statistic indicates which independent variables are statistically significant predictors. Only success $(B=-.611$, Wald $=8.64, p=.003)$ and employees ( $B=.49$, Wald $=3.98, p=.046)$ demonstrate significance. When interpreting the difference across clusters, cluster one is used as the basis for comparison; thus, clusters two and three are compared with cluster one. Cluster one demonstrates a strong focus on success, cluster two indicates no emphasis on success, and cluster three appears highly employee oriented. Therefore, firms focusing on success are more likely to sponsor individuals, environment, health and education while firms concentrating on employees are more inclined to sponsor entertainment, sport, religious, business and community oriented events/activities.

DV2: "Will Not" Sponsor Category. The same process of multinomial regression was completed for the three cluster Will Not solution. Unlike DV1, this model was nonsignificant, suggesting that mission statement themes cannot predict what will not be sponsored.

\section{Discussion}

In summary, this study demonstrates that mission statement content, or differing corporate identities as expressed in mission statements predict, in regression analysis, unique content within sponsorship policies. In other words, a firm's corporate identity as manifest attributes that reflect its highest values (Whetten, 2006) influence what type of sponsorship it will undertake. While this finding is preliminary and exploratory in nature, it provides grounding for future work on the identity-policy image link.

Following the content analyses, factor analysis performed on the 13 original mission statement categories produce the overarching themes of success, an employee focus, innovation, leadership, and responsibility. These factors account for almost $53 \%$ of the variation in the total data set. Considering the sample frame was composed of firms differing in industry, location, focus and size, this is a reasonably strong measure. Similarly, thirteen Will and Will Not sponsorship categories extracted from the data were factor and cluster analyzed. The Will sponsorship categories produced five factors entitled Sport/Entertainment, Individuals/ Environment, Charity, Business/Community, and Health/Education. The Will Not category produced four factors referred to as Political/Religion/Individuals/Business/Other, Health/Education/Arts, Community/Sport, and Entertainment. These factors explained almost $60 \%$ and $58 \%$ of the variance within the data respectively; again, fairly strong measures given the disparity of sample characteristics. These interim steps of analysis (before the multinomial regression, again please refer to Figure 1) show that the independent and dependent variables offer good representation of firms' mission statements and sponsorship policies.

Multinomial regression analysis investigated how mission statement themes predict sponsorship types. Results suggest that an employee focus and a success 
orientation are discriminating elements of corporate identity in terms of differentiating sponsorship policy specifications. Employee focus explains $14 \%$ of variation, while company success explains $11 \%$, accounting for $25 \%$ of total variance in the data. Given that sponsorship selection will ultimately be driven by a number of factors beyond corporate identity, such as budget, objectives, and management preferences and possibly brand image goals, $25 \%$ of variance explained is a surprisingly large figure. This reinforces the hypothesis that, to some degree, corporate identity is expressed in sponsorship policy and thus sponsorship practice.

Aside from indicating which corporate identity orientations are significant in predicting different policy specifications, the multinomial regression analysis also indicates how these sponsorship policies differ. For example, a firm holding a strong success orientation engages in sponsorships of individual athletes, the environment, health and education. Initially, some of these sponsorships might seem counterintuitive. Previous literature and general observation feeds the assumption that financially driven firms would be more likely to undertake sponsorships, such as sport teams and entertainment, that are viewed by audiences to be commercially oriented (see Meenaghan \& Shipley, 1999). However, contemporary trends in corporate citizenship, management, and marketing suggest otherwise and help explain this apparent reversal of logic.

In recent times, mounting pressure applied to large scale organizations is forcing companies to strike a balance between improving consumer and society's wellbeing (Mohr, Webb, \& Harris, 2001). Companies have complied accordingly with these pressures and corporate support of social causes surpassed (US) \$1 billion in the 1990s (Barone, Miyazaki, \& Taylor, 2000). Furthermore, there is a direct link between socially responsible companies and increasing investment (Larson, 1999), sales (Barone et al., 2000), and financial performance (McGuire, Sundgren, \& Schneeweis, 1988), supporting the notion that consumers are more likely to support socially oriented companies.

From a strategic perspective, the image link between successful individual athletes and success oriented firms is more straightforward and decidedly compelling. Financially driven firms match well to the upscale demographics of individually oriented sports such as golf and tennis. Striving to "be the best" is exemplified by the struggles and successes of the individual athlete. This is illustrated in the extensive role that golfer, Tiger Woods has played in the repositioning of financial consulting firm, Accenture Inc. (Podmolik, 2004). In conjunction with its sponsorship investments, Accenture is moving from the tagline of "Innovation delivered" to "High performance" (Podmolik, 2004, p. 12) thus expressing through sponsorship and advertising their focus on high performance business strategy.

In contrast, internal marketing theory helps explain policy specifications of sporting and entertainment sponsorships. Internal marketing is a strategy enacted to motivate employees to adopt a heightened customer orientation (Varey, 1995). In particular, team sport sponsorships are highly conducive to internal marketing (Hickman, Lawrence, \& Ward, 2005), with outcomes including increased motivation (Maynard, 1995), attention and appreciation for company ideals (Cassidy, 2001), and a positive influence on employee perception, attitude, behavior and identification with a firm (Hickman et al., 2005). Thus, firms are beginning to leverage their resources by combining internal and external marketing efforts beneath the same, overarching marketing strategy (Varey, 1995). 
The identical statistical process of factoring, clustering, and multinomial logistic regression analysis finds that mission statement themes do not predict what a firm will not sponsor; this analysis was nonsignificant, indicating that corporate identity (mission statement themes) does not predict what a firm avoids sponsoring. Therefore, corporate identity (as expressed in mission statements) only shapes a firm's affirmative sponsorship policies as opposed to their avoidance policies. This is not surprising since mission statements typically contain visions and values but not antivalues. Further, this finding is consistent with Whetten's (2006) conceptualization of distinguishing identity claims as "attributes used by an organization to positively distinguish itself from others" (p. 222).

\section{Theoretical and Practical Implications}

The research presented here responds to a call for research on sponsorship policy (Cornwell et al., 2005). The findings here suggest that sponsorship policies, previously discussed largely in relationship to brand image development, are also relevant when considering corporate image. This fact suggests that, with regard to sponsorship, corporations have another challenge in managing multiple identities (Balmer \& Greyser, 2002). While most brands under a corporate umbrella might be thought to be in keeping with the corporate parent, this is not always the case. Additional research in this area is justified.

Theoretically, this work argues that sponsorship can play a role in the various processes of organizational identity dynamics discussed by Hatch and Schultz (2002). In particular, the empirical work demonstrates how sponsorship selection as found in sponsorship policies expresses identity claims as found in mission statement themes. While past research has argued that sponsorship can help form corporate identity and has shown some evidence for the impact of sponsorship on identity, this is the first empirical work to attempt to locate the link between identity claims and sponsorship policy.

Empirically the finding that clear distinctions in sponsorship policy stem from mission statement themes opens a new area of research. If one accepts that mission statements reflect the sanctioned or managerial identity claims, and one reflects on the development of sponsorship policy, perhaps from the marketing department, perhaps from the corporate communications or public relations division of a company either with or without managerial oversight, the found relationship is significant. This opens questions on the additional potential possible in forming an integrated marketing communications program and its role in the development of corporate image. For example, could greater cohesion in corporate image be achieved through greater attention to crafting these policy documents?

The practical nature of this study gives rise to several implications for sponsorship management. Firstly, we must recognize that because sponsorship policy at this stage of development requires interaction with firms rather than their agents or agencies, there is practical pressure to make this policy public. This makes sponsorship policy different from many other company instruments. This study found a relatively low incidence of easily located sponsorship policies on company websites. Therefore, the first practical implication of this research is to stress 
to marketing managers the importance of policy availability and direction. Given that the majority of sponsorships are undertaken to enhance or create certain corporate images, it seems a missed opportunity that so few firms use a policy that sets guidelines as to how to achieve such objectives. Even for website visitors who ultimately do not become corporate partners, this is an opportunity to communicate to a wide array of groups who feel they have some potential connection to the firm. Alternatively, it could be the case that some firms would like to keep their sponsorship policy confidential for political or strategic reasons. Thus, there may be firms with mission statements and sponsorship policies not available online and they may vary systematically from those examined in this study.

Another implication is the apparent usefulness of sponsorship in internal marketing either implicitly or explicitly targeting employees. If managers are looking to motivate and boost morale within the workplace, this research suggests that sponsorship of a sporting team can achieve this outcome (corroborating Hickman et al., 2005). Furthermore, the results here suggest that managers of these types of firms (i.e., employee oriented) are combining socially responsible and commercially driven sponsorships (e.g., sports) to conform to the trend of increased socially responsible practices.

\section{Limitations and Future Research Directions}

This research is unable to predict what a firm will not sponsor according to its corporate identity. In addition, the current study fails to provide a rich explanation of firm behavior as it found nonsignificance in industry, firm size, presence, focus (B2B or B2C) and rank in Fortune 500. The failure to find any demographic differences in policy specification offers mixed implications. From a more pessimistic perspective, the inability to draw parallels between particular sponsorship specifications and firm demographics is somewhat misaligned with other literature suggesting that this relationship exists (e.g., Dolphin, 2003). On the other hand, it builds strength to the argument posited in this paper that corporate identity is a predictor of sponsorship specifications as it is the foundation on which sponsorship policy is laid and thus does not hinge on industry characteristics.

In terms of research design, one limitation is the sample frame and size. As mentioned previously, Fortune 500 firms were used as a sample base. While these firms possessed the right characteristics for the purposes of this study, for example, their budgets and websites to allow sponsorship investment as a collective, they are reflective of the 500 largest public corporations in the United States. It is difficult to draw parallels between the operations of a global firm and the operations of a small to medium sized enterprise. It is probable that a large scale corporation would have enough internal diversity such that particular product category relationships to sponsorship are not disclosed.

Construct validity is weakened by the use of proxy measures of corporate identity since there are many elements involved within identity (Balmer, 1995). While mission statements are a key element of corporate identity and thus considered a reasonable surrogate, the proxy measure fails to capture all of the associated dimensions of identity. To overcome this issue, further research should use mission statements in conjunction with other measures; perhaps actually surveying the companies and asking for their definition of corporate identity to ensure 
the full construct is measured. Similarly, it could be argued that sponsorship policies are only a proxy of what firms actually sponsor. With this in mind, future studies might seek to learn about the sponsorships actually undertaken and consider the degree to which they match the espoused sponsorship policy.

A final shortcoming of this study is the fact that it is based on available data. Secondary data are used and all constructs and relationships are sculpted from it. Several issues are associated with conducting research of this type (Malhotra, Hall, Shaw, \& Oppenheim, 2002). One issue relevant to this study is the accuracy of the data. Secondary data are formed for a purpose other than that of the focal study and therefore cannot always be considered accurate or current. Also while limiting data collection to only online sponsorship policies meant that the policies were all intended for public consumption and thus could be thought of as potentially expressing and impressing identity claims publicly, firms in the sample could have possibly held a sponsorship policy that was not recovered. While this may have been the case, demands by stakeholders, and in particular sport, cause and arts properties seeking sponsorships, have pushed firms to make these policies readily available if for no other reason than to reduce the workload associated with complying with requests for them. Other researchers have reported that because firms receive thousands of sponsorship requests per year, obtaining responses from fax and e-mail requests is decidedly difficult (Cornwell et al., 2001).

\section{Conclusion}

In summary, this study investigates the relationship between corporate identity as expressed in mission statements, sponsorship policy and consequent corporate image. Corporate identity was found to predict what type of sponsorships a company will undertake. Given that the vast majority of sponsorships examined were of sport, one of the most significant strategic findings is in this area. Specifically with regard to sport, companies that are focused on financial success will be more inclined to engage in sponsorship of individual athletes, whereas those focused on employees favor a large entertainment component such as is found in team sports. The implications of this research are twofold: (1) theoretically, it introduces an entirely new direction for studies that can build on and extend these findings as it is an almost unexamined area in sponsorship literature; and (2) it equips marketing managers with a greater understanding of how to formulate policy with the aim of projecting desirable and positive corporate images to the public.

\section{References}

Albert, S., \& Whetten, D.A. (1985). Organizational identity. Research in Organizational Behavior, 7, 263-295.

Alessandri, S.W. (2001). Modeling corporate identity: A corporate explication and theoretical explanation. Corporate Communications, 6, 173-182.

Amis, J. (2003). Good things come to those who wait: The strategic management of image and reputation at Guinness. European Sports Management Quarterly, 3, 189-214.

Balmer, J.M.T. (1995). Corporate branding and connoisseurship. Journal of General Management, 21, 24-46. 
Balmer, J.M.T., \& Greyser, S.A. (2002). Managing the multiple identities of the corporation. California Management Review, 44(3), 72-86.

Barney, J.B., \& Stewart, A.C. (2000). Organizational identity as moral philosophy: Competitive implications for diversified corporations. In M. Schultz, M.J. Hatch, \& M.H. Larsen (Eds.), The expressive organization: linking identity, reputation and the corporate brand (pp. 11-35). Oxford, UK: Oxford University Press.

Barone, M.J., Miyazaki, A.D., \& Taylor, K.A. (2000). The influence of cause related marketing on consumer choice: Does one good turn deserve another? Academy of Marketing Science, 28, 248-262.

Becker-Olsen, K.L., \& Hill, R.P. (2006). The impact of sponsor fit on brand equity. Journal of Service Research, 9, 73-83

Berger, I.E., Cunningham, P.H., \& Drumwright, M.E. (2006). Identity, identification, and relationship through social alliance. Journal of the Academy of Marketing Science, $34,128-137$.

Brewer, M.B. (2003). Optimal distinctiveness, social identity and the self. In M.R. Leary \& J.P. Tangney (Eds.), Handbook of self and identity (pp. 480-491). New York: Guilford Press.

Cassidy, H. (2001). McDonald's '02 Olympic campaign extols ideals of athletes, employees. Brandweek, 42(47), 4.

Cheney, G., \& Christensen, L.T. (2004). Organizational identity: linkages between internal and external communications. In M.J. Hatch \& M. Schultz (Eds.), Organizational identity (pp. 510-557). New York: Oxford University Press.

Cornwell, T.B. (1997). The use of sponsorship-linked marketing by tobacco firms: International public policy issues. The Journal of Consumer Affairs, 31, 238-254.

Cornwell, T.B., \& Maignan, I. (1998). An international review of sponsorship research. Journal of Advertising, 27(1), 1-22.

Cornwell, T.B., Roy, D., \& Steinard, E.A. (2001). Exploring managers' perceptions of the impact of sponsorship on brand equity. Journal of Advertising, 30(2), 41-51.

Cornwell, T.B., Weeks, C.S., \& Roy, D.P. (2005). Sponsorship linked marketing: Opening the black box. Journal of Advertising, 34(2), 21-42.

Dewhirst, T., \& Hunter, A. (2002). Tobacco sponsorship of Formula One and CART auto racing: Tobacco brand exposure and enhanced symbolic imagery through co-sponsors' third party advertising. Tobacco Control, 11, 146-150.

Dolphin, R.R. (2003). Sponsorship: Perspectives on its strategic role. Corporate Communications, 8, 173-187.

Dutton, J.E., \& Dukerich, J.M. (1991). Keeping an eye on the mirror: Image and identity in organizational adaptation. Academy of Management Journal, 43, 517-554.

Gilsdorf, J.W. (1987). Written corporate communication policy: Extent, coverage, costs and benefits. The Journal of Business Communication, 24, 35-52.

Grey, E.R., \& Balmer, J.M.T. (1998). Managing corporate image and corporate reputation. Long Range Planning, 31, 695-702.

Grimes, E., \& Meenaghan, T. (1998). Focusing commercial sponsorship on the internal corporate audience. International Journal of Advertising, 17, 51-74.

Gwinner, K., \& Eaton, J. (1999). Building brand image through event sponsorship: The role of image transfer. Journal of Advertising, 28(4), 47-58.

Hackley, C. (1998). Mission statements as corporate communications: the consequences of social constructionism. Corporate Communications, 3, 92-98.

Hair, J.F., Anderson, R.E., Tatham, R.L., \& Black, W.C. (1998). Multivariate data analysis. New Jersey: Prentice Hall.

Hatch, M.J., \& Schultz, M. (2002). The dynamics of organizational identity. Human Relations, 55, 989-1018.

Henderson, P.W., \& Cote, J.A. (1998). Guidelines for selecting or modifying logos. Journal of Marketing, 62, 14-30. 
Henderson, P.W., Giese, J.L., \& Cote, J.A. (2004). Impression management using typeface design. Journal of Marketing, 68, 60-72.

Hickman, T.M., Lawrence, K.E., \& Ward, J.C. (2005). A social identities perspective on the effects of corporate sport sponsorship on employees. Sport Marketing Quarterly, $14,148-157$.

Inc, I.E.G. (2005). '06 Outlook: Sponsorship growth back to double digits. IEG Sponsorship Report, 24, 4-5.

Insch, G.S., Moore, J.E., \& Murphy, L.D. (1997). Content analysis in leadership research: Examples, procedures and suggestions for future use. The Leadership Quarterly, 8(1), $1-25$.

Javalgi, R.G., Traylor, M.B., Gross, A.C., \& Lampman, E. (1994). Awareness of sponsorship and corporate image: An empirical investigation. Journal of Advertising, 23(4), 47-58.

Kover, A.I. (2001). The sponsorship issue. Journal of Advertising Research, 41, 5-15.

Lachowetz, T., Clark, J., Irwin, R., \& Cornwell, T.B. (2002). Cause-related sponsorship: A survey of consumer/spectator beliefs, attitudes, behavioral intentions, and corporate image impressions. American Marketing Association Conference Proceedings 13, 14-20.

Larson, T. (1999). SRI Trends Report. Social Investment Forum. ([News Release])

Leuthesser, L., \& Kohli, C. (1997). Corporate identity: The role of mission statements. Business Horizons, 40, 59-66.

Malhotra, N., Hall, J., Shaw, M., \& Oppenheim, P. (2002). Marketing research. Malaysia: Prentice Hall.

Maynard, R. (1995). How to score points with sports marketing. Nation's Business, 6, 52.

McDonald, C. (1991). Sponsorship and the image of the sponsor. European Journal of Marketing, 25, 31-38.

McGuire, J.B., Sundgren, A., \& Schneeweis, T. (1988). Corporate social responsibility and firm financial performance. Academy of Management Journal, 31, 854-872.

Meyer, J.W., \& Rowan, B. (1977). Institutional organizations: formal structure as myth and ceremony. American Journal of Sociology, 83, 340-363.

Meenaghan, T., \& Shipley, D. (1999). Media effect in commercial sponsorship. European Journal of Marketing, 33, 328-347.

Mohr, L., Webb, D.J., \& Harris, K.E. (2001). Do consumers expect companies to be socially responsible? The impact of corporate social responsibility on buying power. The Journal of Consumer Affairs, 35, 45-72.

Motion, J., Leitch, S., \& Brodie, R.J. (2003). Equity in corporate co-branding: The case of adidas and the All Blacks. European Journal of Marketing, 37(7/8), 1080-1094.

Peyrefitte, J., \& David, F.R. (2006). A content analysis of the mission statements of United States firms in four industries. International Journal of Management, 23(2), 296301.

Podmolik, M. E. (2004). Accenture turns to Tiger for global marketing effort. $B$ to $B$, 89(12), 12.

Rajaretnam, J. (1994). The long-term effects of sponsorship on corporate and product image: Findings of a unique experiment. Marketing and Research Today, 22(1), 6273.

Ran, B., \& Duimering, P.R. (2007). Imaging the organization language use in organizational identity claims. Journal of Business and Technical Communication, 21, 155-187.

Ruth, J.A., \& Simonin, B.L. (2003). "Brought to You by Brand A and Brand B": Investigating multiple sponsors' influence on consumers' attitudes toward sponsored events. Journal of Advertising, 32(3), 19-30.

Saunders, J. (1994). Cluster analysis. Journal of Marketing Management, 10, 13-28.

Stipp, H., \& Schiavone, N.P. (1996). Modeling the impact of Olympic sponsorship on corporate image. Journal of Advertising Research, 36, 75-87. 
Varey, R.J. (1995). Internal marketing: A review and some interdisciplinary research challenges. International Journal of Service Industry Management, 6, 40-63.

Walliser, B. (2003). An international review of sponsorship research: Extension and update. International Journal of Advertising, 22, 5-40.

Whetten, D.A. (2006). Albert and Whetten Revisited: Strengthening the concept of organizational identity. Journal of Management Inquiry, 15, 219-234. 